Article

\title{
Potential and Realized Absorptive Capacity as Complementary Drivers of Green Product and Process Innovation Performance
}

\author{
Gema Albort-Morant ${ }^{1,2, *(1)}$, Jörg Henseler ${ }^{2,3}$ (1) , Gabriel Cepeda-Carrión ${ }^{4}$ (i) and \\ Antonio L. Leal-Rodríguez ${ }^{2,4}$ (iD \\ 1 Department of Social Sciences, Centro Universitario San Isidoro, 41092 Seville, Spain \\ 2 Faculty of Engineering Technology, University of Twente, 7500 AE Enschede, The Netherlands; \\ j.henseler@utwente.nl (J.H.); lealrodriguez@us.es (A.L.L.-R.) \\ 3 Nova Information Management School, Universidade Nova de Lisboa, 1070-312 Lisbon, Portugal \\ 4 Departamento de Administración de Empresas y Marketing, Universidad de Sevilla, 41018 Seville, Spain; \\ gabi@us.es \\ * Correspondence: galbort@centrosanisidoro.es
}

Received: 6 November 2017; Accepted: 30 January 2018; Published: 1 February 2018

\begin{abstract}
Nowadays, companies need to absorb new knowledge from external sources to grasp environmental issues. However, the internal mechanisms through which external knowledge is turned into green innovations remain scarcely addressed. Hence, this paper aims to investigate the relationships between the two dimensions of absorptive capacity (potential and realized) with green products and process innovation performance. This study contributes to the literature by disentangling how companies need to acquire, assimilate, transform and exploit external environmental knowledge to develop green innovations. To this aim, this empirical study is based on a sample shaped by 112 firms belonging to the Spanish automotive components manufacturing sector. The results provide evidence to show that potential and realized absorptive capacities are positively related to both green product innovation performance and green process innovation performance.
\end{abstract}

Keywords: absorptive capacity; green innovation performance; partial least squares

\section{Introduction}

Nowadays, companies are intensely requested to comply with the environmental regulations established by Kyoto Protocol, Montreal Convention, and Waste Electronics and Electrical Equipment (WEEE) among others.

As is widely acknowledged, innovation develops, each time, into a more pivotal role, while driving organizational competitiveness. The new knowledge economy, the information society and the increasing globalization of markets require companies to develop innovative effort. In addition, firms ought to carry out this innovative endeavor without disregarding the environmental impact they exert through their operations and activities. Thus, organizations may promote a shift into the more refined notion of green innovation. Green growth involves fostering economic growth and development while ensuring that natural assets still provide the resources and environmental services on which global wellbeing depends. The growing collective awareness regarding the sustainability of future economic growth patterns reinforces the claim for a greener economic model. Along this vein, by pushing the frontier outward, green innovation might help to decouple economic growth from natural resource exhaustion. The firms' fostering of green innovations may also lead to innovative ideas, new entrepreneurs and new business models, thus contributing to shaping new markets, products, services or processes and ultimately, to the conception of new jobs. Green innovation might then be a strategic issue in the path of driving environmentally sustainable growth [1]. 
The environmental protection concept has gained attention in the management agenda due to the significant environmental awareness increase experienced by society over previous decades. This has contributed to set the basis for green innovation strategies through which firms must develop green-related innovations aimed at mitigating or avoiding environmental damage [2,3]. Corporate environmental strategies vary from reactive-essentially designed to comply with legal requirements and implement controls - to proactive strategies-those that comprise deliberate and voluntary eco-efficient practices aimed at reducing energy consumption, waste generation and emissions [4]. Thus, there exist abundant opportunities for firms aiming to green their products and processes [5].

In this sense, companies that proactively embrace green innovation strategies might be able to encompass a sustainable competitive advantage [6].

The term, "green innovation performance", as defined by Lai et al. [7], is the outcome derived from all the innovative environmental management efforts, in line with the firm's wish to satisfy environmental protection requirements. Later, reference [8] defined this term as "hardware or software innovation that is related to green products or processes, including innovation in technologies that are involved in energy saving, pollution prevention, waste recycling, green product design, or corporate environmental management" (p. 332). This study divides the green innovation construct into: (1) green product innovation performance (GIPr) and (2) green process innovation performance (GIPc). On one hand, green product innovation performance is focused on energy-saving, pollution prevention, waste recycling and non-toxic or green product design. To this aim, companies choose materials that produce the least amount of pollution, consume the least amount of energy and resources, and elaborate a product which is easy to recycle, reuse and decompose. On the other hand, green process innovation performance deals with the firm's endeavors towards the implementation and development of greener process, in an attempt to reduce the company's manufacturing processes' emission of hazardous substances or waste, recycle waste and emission that allow them to be treated and re-used, reduce the consumption of water, electricity, coal or oil; and optimize the use of raw materials [7].

Current research shows the emergence of a firm's absorptive capacity (ACAP) as a fundamental dynamic capability for improving innovation in organizations [9]. The literature in the field of organizational learning reports that organizations that possess relevant prior knowledge are likely to have a better understanding of new technology that can generate new ideas and develop new products, services and processes [10]. Therefore, absorptive capacity might enable better assessment of the benefits derived from new technologies with regard to their ability to reduce potential liability costs, legal fees, or product take-back costs, or to leverage production efficiencies and waste reduction [11]. Consequently, these authors suggest that firms not only need to acquire knowledge on environmentally proactive technologies, they also need to implement processes that help them to absorb key environmental knowledge.

Absorptive capacity, or the ability of organizations to create knowledge, is frequently cited as a requirement for innovation [12] and has recently been spotted as an important driver of green innovation adoption [13], because it allows firms to enhance their ability to comprehend, connect, combine, identify and apply environmental knowledge. ACAP is conceptualized as a multidimensional construct that creates innovation-related value for the organization. At a first-order level of analysis, it includes a set of four capabilities: (i) acquisition; (ii) assimilation; (iii) transformation; and (iv) exploitation. The two first constitute an organization's potential absorptive capacity (PACAP). And the other two dimensions constitute an organization's realized absorptive capacity (RACAP) [14]. Therefore, PACAP embodies the integration of external knowledge within a firm's knowledge repository, while RACAP represents its combination, utilization and application $[15,16]$. While these specific multidimensional levels of ACAP have advanced our understanding of the concept $[17,18]$, there is, in particular, a lack of empirical research specifically considering these dimensions [19].

In this study, we will adopt [13] this conceptualization of absorptive capacity because we want to offer an empirically tested model to explain the enhancement of the two dimensions of absorptive capacity (PACAP and RACAP) with the two dimensions of green innovation performance (GIPc 
and GIPr). These relationships remain scarcely explored and lack a solid empirical basis [20-22]. From available studies, a relevant gap in research aimed at providing a deeper understanding of the effects exerted by the two dimensions of absorptive capacity on green product and process innovation performance was identified. Hence, this paper finds its justification in the existent gap in research conducted with empirical data.

Specially, we intend to provide an answer to the following research questions: (i) How does a firm's absorptive capacity influence the creation of its green innovation through processes and products; (ii) is a firm's realized absorptive capacity a mediating variable in the PACAP-GIPr and PACAP-GIPc links? Thus, we seek to reach a better understanding of the influential relationships between PACAP, RACAP, GIPr and GIPc. Therefore, our aim is to build a theoretical and empirical contribution to the literature regarding the conceptualization, measurement, and interrelationships between these variables.

The methodology employed in this work involves a quantitative empirical survey of small and medium companies (SMEs) from the Spanish automotive components manufacturing sector (ACMS), based on a final random sample comprising 112 companies. We used Partial Least Squares (PLS), a variance-based structural equation modeling to test the hypotheses proposed in our research model [23].

The following section reviews the scientific literature concerning the links between potential absorptive capacity, realized absorptive capacity, green innovation product performance and green innovation process performance, and subsequently posits the research model and hypotheses. Then, this study introduces the research methodology and presents the PLS results, together with insights from mediation analysis. The final section of the paper discusses the results and suggests various implications and limitations, before concluding the article.

\section{Conceptual Framework and Hypotheses}

\subsection{Absorptive Capacity}

Referring to the seminal work of Cohen and Levinthal [12], the term, "Absorptive capacity" (ACAP), can be defined as a firm's ability to value, assimilate, and apply new knowledge. Further, [24,25] it is the firm's capacity to learn and resolve difficulties. A later study, developed by [13], supposed an important reconceptualization of absorptive capacity. In this study, we will focus on the theory proposed by [14] that distinguish between two dimensions of ACAP-PACAP and RACAP. These authors also suggested distinguishing among four subsets that compose a firm's ACAP: (i) acquisition; (ii) assimilation; (iii) transformation and (iv) exploitation. A definition of these four capabilities is offered in the following paragraphs.

(i) Acquisition capacity: this term refers to the company's identification and acquisition of valuable external knowledge. This is consistent with the view of the process of identification and evaluation of external knowledge in [12] (p. 128). They theorized this to be the ability to evaluate and utilize previous knowledge, to identify, assimilate and apply new information value.

(ii) Assimilation capacity: this concept has come to be used to refer to a firm's habits, methods, processes and routines that lead them to effective assessment, processing and understanding of the information captured from external sources [24]. This capability is deeply rooted in the individual's understanding and knowledge interpretation. In this way, knowledge assimilation is based on a firm's ability to grasp new external knowledge and make sense of it.

(iii) Transformation capacity: this term refers to the combination of the newly acquired external knowledge and the firm's prior related knowledge. Concretely, [14] (p. 190) suggest that this dimension "denotes a firm's capability to develop and refine the routines that facilitate combining existing knowledge and the newly acquired and assimilated knowledge". This phase is considered to be the most relevant. This is achieved by adding or deleting knowledge, or by the simple interpretation of knowledge in a different way. 
(iv) Exploitation capacity: this concept is defined "as an organizational capability that is based on the routines that allow firms to refine, extend, and leverage existing competencies or to create new ones by incorporating acquired and transformed knowledge into its operations" [14] (p. 190). Reference [11] uses the term, "exploitation", to refer to the application of new external knowledge for commercial ends. Therefore, if all the other phases do not lead to knowledge exploitation, they will not have been proven to be very useful.

In [14]'s model of absorptive capacity, potential (i.e., acquisition and assimilation capabilities) absorptive capacity and realized absorptive capacity (i.e., transformation and exploitation capabilities) are modeled as complementary subsets of absorptive capacity that drive performance indicators, such as competitive advantage, strategic flexibility or innovation (see Figure 1).

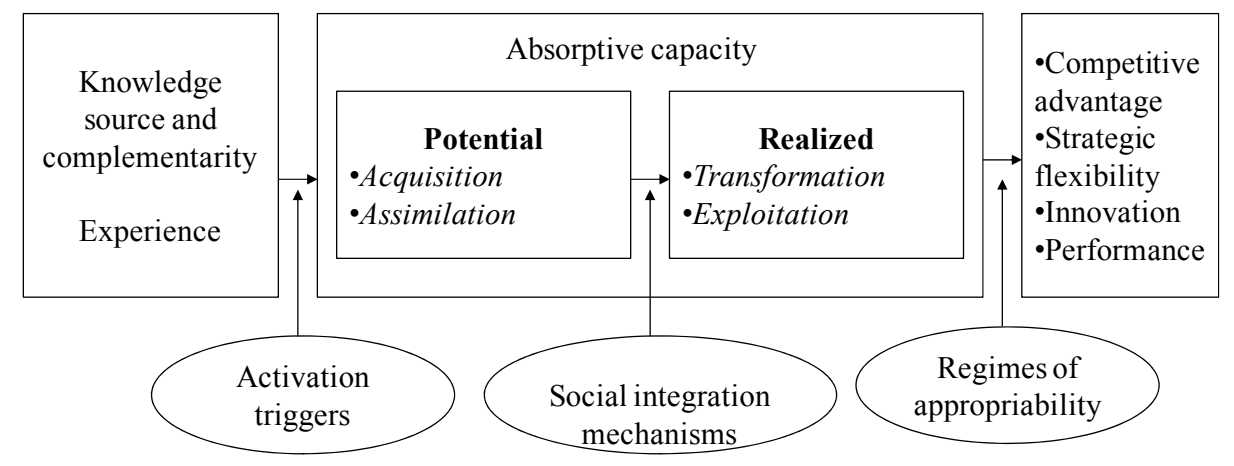

Figure 1. The model by Zahra and George. Source: [14] (p. 192).

\subsection{Green Innovation Performance}

The term, "green", is usually applied in a switchable manner with other related terms, such as "eco" or "pro-environmental", and it is largely intended to indicate concern about the physical environment. Along this line, when stakeholders proactively engage in this kind of behaviour, they can be labelled as "green stakeholders". In the case of customers (i.e., "green customers"), their purchasing behaviour is incrementally becoming more predisposed by issues such as environmental concern, sustainability, pollution reduction, energy saving or recycling [4].

But then, what should we understand by green innovation? This concept is gradually attaining plenty of attention, not only from scholars devoted to the study of business management and economic policy, but also from practitioners aimed at greening their firms' strategies and operations. However, green innovation is a relatively novel phenomenon, which may hence be regarded as intricate, diffuse and prone to different interpretations. Thus, the existence of some confusion regarding the diverse notions and terms employed to describe innovations aimed at reducing the negative impacts of humans and business on the environment must be recognized [26]. Reference [27] were pioneers in the introduction of the term "eco-innovation", in their book 'Driving Eco-innovation: A Breakthrough Discipline for Innovation and Sustainability'. These authors coined this term to refer to innovations in the form of new products and processes that lead to superior customer and business value, while substantially reducing environmental impact [4]. From this moment, the term "eco-innovation"—also named "environmental innovation", "green innovation" or "sustainable innovation" - has usually been employed to categorize innovations that contribute to the preservation of a sustainable environment through the development of ecological enhancement [28].

At this point, it must be underlined that green innovation entails several characteristics that make it inherently different, although related, to general innovation. The etymological foundation of the term innovation roots in the Latin term "innovare", which involves a certain degree of transformation of something, through the introduction of some novelty. Reference [29] posits that innovating involves developing new products, services or processes. In addition, reference [30] argues that innovation comprises a new way of doing what is currently being commercialized. Therefore, innovation 
encompasses both invention and commercialization stages. The main feature that characterizes green innovation and consequently, differentiates it from general innovation lies in the environmental benefit derived from the previous. In this vein, the OECD/Eurostat Oslo Manual [31] conceives green innovation as the implementation of novel, or substantially enhanced products, processes, marketing methods, organizational structures and institutional arrangements which, both deliberately or unintentionally, lead to environmental improvements compared to relevant alternatives. Likewise, reference [32] considers that green innovations should not be limited to products or services launched for purely environmental reasons. According to these authors, green innovations cover a broader spectrum that embraces all innovations that lead to sustainability outcomes or environmental benefit, whether intentional or accidental.

With the increase in environmental concerns expressed by customers, manufacturers and product designers create designs that are less polluting or harmful for the environment. Therefore, green innovation consists of all type of innovations that donate to the generation of products, services or processes to decrease the damage, effect and decline of the environment, and at the same time, enhance the use of natural resources.

Authors, like $[33,34]$, suggest that green innovation may possibly raise companies' productivity and maximize their use of resources, becoming consequently more competitive from the improvement and sustainment of competitive advantages rooted in the corporate image improvement and the development of new markets, while gratifying the requirement of environmental protection [7,35].

Recently, reference [36] defined green innovation is "a strategic need for firms and it offers a great opportunity for meeting buyers' wishes without harming the environment" (p. 448). Hence, the conceptualization of green innovation has been stimulated from more resource-oriented descriptions to a more comprehensive framework that incorporates the firm's compliance with the stakeholders' green requirements and demands.

Numerous authors, such as $[8,37,38]$, among others, have distinguished between several typologies of green innovation: products, processes, technological and managerial. However, our study focuses on green product innovation and green process innovation. References [8,35] difference green innovation into green product innovation and green process innovation.

These authors clarify the process of innovation as a process that adapts the design of an existing product that reduces the harmful impact on the environment. This requires adaption of the production process of the company throughout the whole process of acquisition, production and distribution of the products. Product innovation is defined as the introduction of novel products and services that do not produce any contamination or have minimal negative consequences, using products and biodegradable materials, and are efficient in the use of energy, water or any other natural resource.

\subsection{The Effects of Absorptive Capacity on the Firm's Green Product and Process Innovation Performance}

Chen et al. [8] define green innovation as the sort of innovation that is aimed at the enhancement of a firm's environmental management performance to satisfy the requirement of environmental protection, and, in this way, enables a business to increase resource productivity through green innovation to make up for environmental costs. The same authors explain that green innovation performance might consist of either green products or the carrying out of green processes.

Therefore, green innovation performance can create or enhance value for the firm through the development of more environmentally innovative products or processes. Green innovation, which might commonly be divided into two subsets (i.e., green product innovation and green process innovation), denotes the activities and policies concerning the development of innovative products and processes aimed at substantially minimizing environmental impacts $[8,39]$.

According to [40], the prior accumulation of knowledge fosters a firm's potential to produce innovation outcomes. The process of applying new knowledge to obtain new products, services or processes usually generates innovation outcomes, such as green innovation performance. 
Reference [12] introduced the concept of absorptive capacity (ACAP) to describe a firm's ability to value, assimilate, and apply new knowledge. Though there exists extensive literature about ACAP, this topic only stimulates significant interest within the academic community in light of [14]'s reconceptualization. The roots of this reconceptualization can be found in the abstract distinction between potential absorptive capacities (PACAP) and realized absorptive capacity (RACAP). Our study is consistent with [14]'s view, which suggests that ACAP comprehends four different but complementary capabilities, namely acquisition, assimilation, transformation, and exploitation. In accordance with their view, PACAP and RACAP involve different capabilities. On one hand, PACAP involves knowledge acquisition and assimilation capabilities, which make a firm open to acquiring and assimilating new externally rooted knowledge [41]. Conversely, RACAP deals with a firm's knowledge transforming and exploiting capabilities. Along this vein, according to [42], PACAP and RACAP are essentially distinct concepts, and consequently, may draw on different objectives, structures and strategies. These diverse capabilities are considered to help the organization to attain a competitive advantage that may lead to superior performance [43].

Following the reasoning in [12] (p. 128) - "the ability to evaluate and utilize outside knowledge is largely a function of the level of prior related knowledge. [ ... ] Prior knowledge confers an ability to recognize the value of new information, to assimilate it, and to apply it to commercial ends"-we posit that green knowledge acquisition deals with a company's capability of identifying and acquiring external environmental knowledge that is critical to its green practices.

Knowledge assimilation is composed of the firm's routines and processes that allow it to analyze processes, interpret, and understand the information obtained from external sources [24]. This second dimension of ACAP consists of the interpretation and understanding of individuals' knowledge. This stage of ACAP approaches the individual level more than the collective one. Specially, knowledge assimilation describes the capacity of understanding new external knowledge and linking it with the prior environmental knowledge base.

Reference [14] (p. 190) explains that transformation capacity is "a firm's capability to develop and refine the routines that facilitate combining existing knowledge and the newly acquired and assimilated knowledge". In this case, transformation stands as the internalization of new external knowledge about environmental practices in existing firms' products and processes.

The last phase has been traditionally considered to be the most important one, since exploitation comprises an organization's capability to refine, extend or leverage its existing competencies, or to create new ones by incorporating acquired and transformed knowledge into its operations and procedures [14].

PACAP includes acquisition and assimilation capabilities for obtaining external environment knowledge. However, obtaining this knowledge does not guarantee the operation of the same. In a second stage, the phases of transformation and exploitation that shape the RACAP dimension serve to reflect the environmental knowledge previously acquired. Therefore, PACAP and RACAP are different concepts that involve very different strategies and structures. While PACAP requires change, flexibility and creativity, RACAP requires control and stability.

Reference [44] suggests that the novelty creation process is composed of two stages, called "invention" and "innovation". On one hand, invention is associated with the creation of a conceptual novelty (i.e., the creation of new ideas or concepts to be applied in a specific business context). This conceptual novelty is essentially rooted in the individuals' tacit knowledge [45]. On the other hand, the innovation phase incorporates the creation of an instrumental originality. This is the process of using the newly-created knowledge and representing it in various forms. The success of this phase depends on a firm's capacity to absorb environmental knowledge and combine it with its own knowledge base.

Several studies posit that the ability to exploit external knowledge effectively constitutes a critical factor for companies with an interest in enhancing innovation outcomes and firm performance $([12,14,15,46-48])$. In addition, the study developed by [42] brings empirical evidence to 
show that PACAP constitutes an antecedent of RACAP and that the latter drives innovation. Concretely, these authors found that "organizational mechanisms associated with PACAP had a significant positive effect on RACAP. Therefore, if the PACAP-enhancing activities provide access to more knowledge, and a greater knowledge base enables the company to search for [ ... ] innovativeness solutions more effectively, then these activities should improve the efficiency of RACAP for new innovation" (p. 1609). However, only a few works have studied the relationship between absorptive capacity and green innovation $([5,13,49])$. However, there is, in particular, a lack of empirical research specifically considering the links between these constructs' dimensions.

On one hand, it is very important that the companies absorb external knowledge about environmental issues, which might serve to reduce or mitigate pollution in their processes of innovation. For example, multiple companies may require absorption knowledge about the measures and international standards set out in the Kyoto Protocol or the norms that they must meet in order to obtain ISO 14001. This new knowledge acquired, in combination with their knowledge base, will allow companies to include innovations into their processes and strategies.

On the other hand, green product innovation performance consists of product improvements related to environmental innovation, and green process innovation performance involves process improvements related to waste and oil recycling, prevention of pollution, etc. [39]. Thus, green products are designed to provide a reliable solution for environmentally-conscious consumers seeking affordable and high quality eco-friendly products [50]. For this reason, companies should absorb external environmental knowledge in order to satisfy environmental protection requirements and to design new, greener products or improve existing ones.

Precisely, in the seminal study developed by [14], the complementarity of both subsets of absorptive capacity (i.e., PACAP and RACAP) in yielding superior performance (i.e., innovation performance, competitive advantage, etc.) is stated. Along this vein, [14] discerned that after an exhaustive revision of prior related research, most empirical studies show significant relationships between a firm's absorptive capacity, its innovative output and other outcomes related to the creation and fulfilment of competitive advantages. As [14] posited, despite the importance of PACAP, RACAP is the primary source of performance improvements. Thus, these outcomes primarily reflect a firm's RACAP efforts. However, as we argue in this paper, the complementarity existing between both subsets of absorptive capacity may lead us to contemplate the degree of influence that PACAP has on a firm's green innovation performance. This is consistent with previous literature assessing the links between both dimensions of absorptive capacity and innovation outcomes (i.e., [51-53]). This decision is consistent with the conceptualization of absorptive capacity in [14] (p. 191): "distinguishing between PACAP and RACAP provides a basis for observing and examining the fluid and nonlinear paths that organizations may follow in developing their core competencies. Making the distinction between PACAP and RACAP can allow researchers to study why some firms fail because of changes in the external environments, such as technological lockout or industry shocks [54], while others thrive under the same conditions".

Hence, this study asserts that PACAP is an antecedent of RACAP, which subsequently exerts a positive influence on green product and process innovation performance and posits the following hypotheses (Figure 2):

H1. Potential absorptive capacity (PACAP) is positively related to realized absorptive capacity (RACAP).

H2. Realized absorptive capacity (RACAP) is positively related to a firm's green product innovation performance (GIPr).

H3. Realized absorptive capacity (RACAP) is positively related to a firm's green process innovation performance (GIPc). 


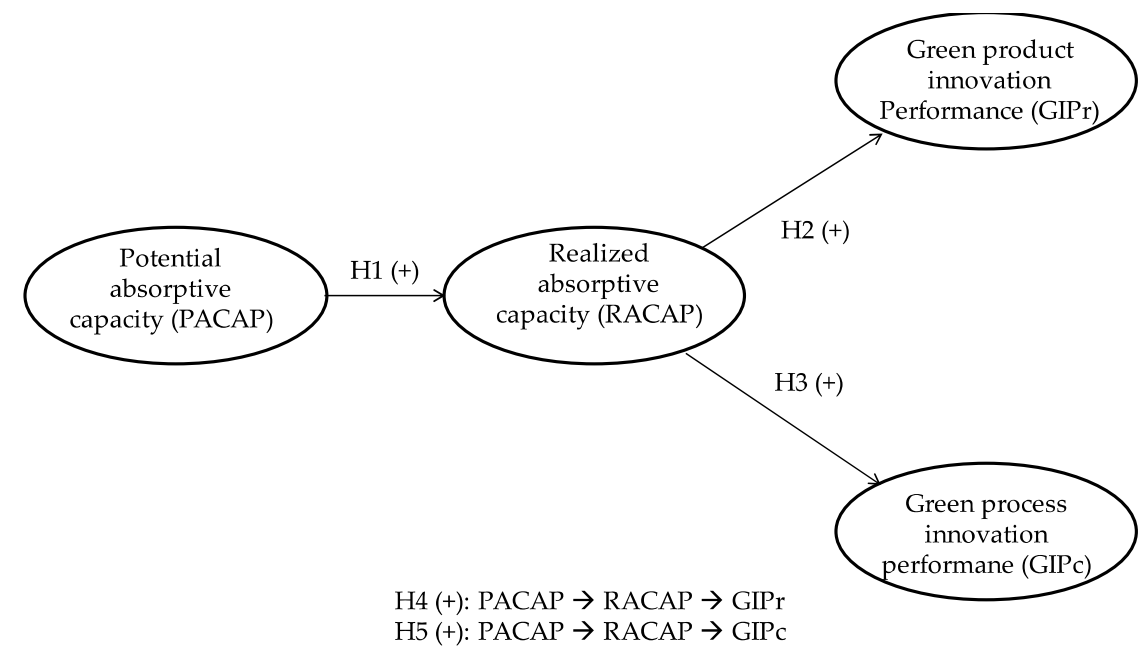

Figure 2. Research model and hypotheses.

\subsection{The Mediating Role of Realized in the Potential Absorptive Capacity-Green Innovation Performance Link}

The four capabilities identified by [14] are distributed between the two constructs or subsections of ACAP. While potential absorptive capacity (PACAP) centers on knowledge acquisition and assimilation, realized capacity (RACAP) focuses on knowledge transformation and exploitation. Knowledge acquisition and assimilation (i.e., PACAP) shapes a firm's capability to value and capture external knowledge, but does not guarantee itself the exploitation of this knowledge. On the other hand, knowledge transformation and exploitation (i.e., RACAP) reflects the firm's capability to leverage the recently absorbed knowledge [55].

The reason for splitting ACAP into its dimensions-potential and realized-roots in the underlying principle that capabilities might be conceived as potentials that are more significant once they are realized [14]. Hence, possessing a capability as a potential is a needed precondition, but not a sole cause for realizing that potential to meet goals. Bearing this in mind, PACAP and RACAP stand as complementary, yet distinct, dimensions of ACAP.

According to [56] (p. 124), "Knowledge alone is not enough. A firm needs to have tools to exploit and appropriate this knowledge embedded in new organizational innovations". This means that knowledge acquisition and assimilation can occur, but this does not guarantee that it will be efficiently transformed and exploited by the firm.

To sum up, the main idea of Zahra and George's thinking is that PACAP and RACAP concepts are complementary - in other words, PACAP and RACAP are both necessary for the effective absorption of external knowledge. According to these authors, a firm may have the capability to acquire external knowledge, but this does not guarantee the exploitation of this knowledge.

On the other hand, a firm may have the capacity to influence and exploit knowledge, but is not able to effectively acquire it. Hence, PACAP and RACAP have different roles, yet their impact is not isolated, but rather, matching. Both subsets of absorptive capacity coexist and participate in the improvement of firm performance. This reasoning led them to rethink the concept of ACAP.

A firm's competence in acquiring and exploiting external knowledge is crucial for the effective development, deployment, and utilization of several innovative capabilities [12]. According to [57], PACAP and RACAP represent fundamental underlying mechanisms for organizational learning, which might ultimately lead to firm innovativeness. Particularly, PACAP might enable innovativeness by sensing and seizing relevant and creative external knowledge. Likewise, RACAP might help in the processing and digestion of external knowledge and turn it into direct inputs for product, service, process, and management innovations. Although these capabilities are complementary, acquisition, and assimilation of external knowledge do not guarantee its effective leverage for innovativeness, 
and firms can be exceptional in transformation and exploitation, while being ordinary in acquisition and assimilation [48].

Considering and integrating all the arguments stated above, we propose the following hypotheses (Figure 2):

H4. Realized absorptive capacity (RACAP) mediates the link between potential absorptive capacity (PACAP) and green product innovation performance (GIPr).

H5. Realized absorptive capacity (RACAP) mediates the link between potential absorptive capacity (PACAP) and green process innovation performance (GIPC).

\section{Method}

\subsection{Sample and Measures}

Bearing in mind the proposed research objectives, a specific industry with a high level of adaptation and creation of green innovation has been selected. The sector of automotive component manufacturers in Spain has specifically been chosen for the following reasons: Firstly, the Spanish automotive sector occupies the second spot among car manufacturers in Europe and the eighth position in the global scenario, uniquely consisting of nine vehicle manufacturers in Spain [58]. Its main strengths are a high level of productivity, qualification of the labor force, investment in $R \& D$, modernization of machinery, and competitiveness of components and auxiliary industries. Second, the sector has the obligation to reduce waste generation as much as possible. For this purpose, companies must comply with environmental legislation. Finally, this industry is characterized by alliances or cooperative actions with their stakeholders. The Spanish components manufacturing firms should maintain strong interdependent relationships within supply chains. For this reason, they must provide a service appropriate to needs and requirements posited by the main vehicle manufacturing companies, for example, reducing residual generation, limiting the use of hazardous substances in their products and processes, designing and producing enhanced pieces that facilitate reutilization and recycling, and developing the integration of recycled materials [59].

The sample comes from a list from Sernauto (www.sernauto.es), the Spanish association of automotive equipment and components manufacturers. From the total of 960 companies gathered by this association, we identified 387 companies who met our selection criteria (i.e., who channel their operations by means of project teams, who make widespread use of external knowledge, and who maintain of strong relationships of interdependence in supply chains). After two mailing efforts, we obtained 112 usable surveys returned (a $28.94 \%$ response rate). This lower-than expected response rate might be explained by the fact that these questionnaires were answered by top executives.

\subsection{Measures}

The questionnaire was designed on the basis of the literature review described in the article. The study uses validated scales from the literature, where the items and responses were on a seven-point Likert scale, ranging from high disagreement to high agreement, to measure the questionnaire items. Appendix A lists the questionnaire items.

The items for measuring ACAP have been validated and used by [42,60], with nine items assessing the intensity and direction of the efforts expended in acquiring and assimilating new external knowledge (PACAP). In addition, RACAP includes the transformation and exploitation of new external knowledge. Reference [42] measured this construct with a total of twelve items that assessed the extent to which firms are able to transform and exploit the newly-acquired knowledge.

To measure green product and process innovation performance (GIPr and GIPc), this study adapts a scale proposed by [8], which operationalizes this construct through eight items. The first four items describe green product innovation, while the four latest contribute to measure green process innovations. 
The four-item measurement instrument developed to evaluate green product innovation performance are: (i) your company chooses the materials of the products that produce the least amount of pollution for conducting product development or design; (ii) your company chooses the materials of the products that produce the least amount of energy and resources for conducting product development or design; (iii) your company uses the least amount of materials to comprise their products for conducting the product development or design; and (iv) your company circumspectly evaluates whether their products are easy to recycle, reuse, and decompose when conducting product development or design.

The four items measuring green process innovation performance are: (i) the manufacturing process of your company effectively reduces the emission of hazardous substances or wastes; (ii) the manufacturing process of your company effectively recycles wastes and emission that can be treated and re-used; (iii) the manufacturing process of your company effectively reduces the consumption of water, electricity, coal, or oil; and (iv) the manufacturing process of your company effectively reduces the use of raw materials.

\subsection{Data Analysis}

Our research model and hypotheses have been tested using Partial Least Squares (PLS), a variance-based structural equation modeling [23]. PLS allows the use of latent variables that represent the concepts posited in theory, and data from manifest variables. These variables are used as input for the statistical analysis that test for evidence for relationships between the latent variables. PLS was therefore used to assess the measurement model-the reliability and validity of the constructs' measures-and to estimate the structural model-the relationships modeled between constructs. The use of PLS is justified by the following reasons from [61]: (i) the research model has reflective variables that are used to define a state where perceived variables are equally dependent upon another variable which is not itself observed. As the model has reflective variables they will be analyzed using Mode A consistent; (ii) the research model uses non-normal data; and (iii) the study utilizes an exploratory analysis. This study used ADANCO 2.0 software [62] for the PLS analysis.

\section{Results}

\subsection{Evaluation of Global Model Fit}

Reference [63] recommend the evaluation of global model fit as the preliminary step of PLS model assessment. If the model fails to fit the data, this implies that the data contains more information than the model conveys. For this purpose, we used ADANCO 2.0.1 [62] to perform several bootstrap-based tests of model fit: (i) the standardized root mean squared residual (SRMR); (ii) the unweighted least squares discrepancy (dULS); and (iii) the geodesic discrepancy (dG). If any of these tests exceed bootstrap-based $95 \%$ (HI95) or 99\% (HI99) percentiles, it is doubtful that the research model is accurate [64]. Our results revealed that the three tests of model fit are below HI99. This implies that this model cannot be rejected [63]. Furthermore, we employed the SRMR [65] as an approximate model fit criterion to reveal whether the discrepancy between the model and the empirical correlation matrix is significant or not. Along this vein, reference [63] suggests a threshold of 0.08 for acceptable fit in PLS-SEM. Our research model attains a relatively acceptable value of 0.059 (Table 1).

Table 1. Global model fit.

\begin{tabular}{cccc}
\hline & Value & HI95 & HI99 \\
\hline SRMR & 0.059 & 0.056 & 0.063 \\
$\mathbf{d}_{\text {ULS }}$ & 1.516 & 1.364 & 1.730 \\
$\mathbf{d}_{\mathrm{G}}$ & 1.858 & 2.168 & 2.636 \\
\hline
\end{tabular}

Notes: SRMR: standardized root mean squared residual (SRMR); dULS: unweighted least squares discrepancy; dG: geodesic discrepancy; HI95: bootstrap-based 95\% percentiles; HI99: bootstrap-based 99\% percentiles. 


\subsection{Measurement Model}

The measurement model involved the assessment of reliability and validity. The measurement model was completely satisfactory (Tables 2 and 3). First, as indicated in Table 2, the indicators and dimensions satisfy the requirement of individual item reliability, because their loadings are greater than 0.707. Second, all multidimensional constructs and dimensions meet the requisite of construct reliability, because their composite reliabilities, measured through the Dijstra-Henseler indicator are greater than 0.7. Third, latent variables attain convergent validity because their average variance extracted (AVE) measures are over the 0.5 level. Lastly, Table 3 shows the test for discriminant validity, following the heterotrait-monotrait (HTMT) criterion. The HTMT ratio of correlations evaluates the average of the heterotrait heteromethod correlations. Several authors suggest a threshold level of HTMT of 0.85 , whereas others propose a value of 0.90 [66]. In this case, we can observe that the constructs of GIPr and GIPc are highly correlated, since their values are superior to the threshold levels of HTMT80 and HTMT95. Therefore, there is evidence that A and B are not distinctive constructs, but two facets or subsets of the ACAP construct.

Table 2. Measurement model: outer loadings, construct reliability, and convergent validity.

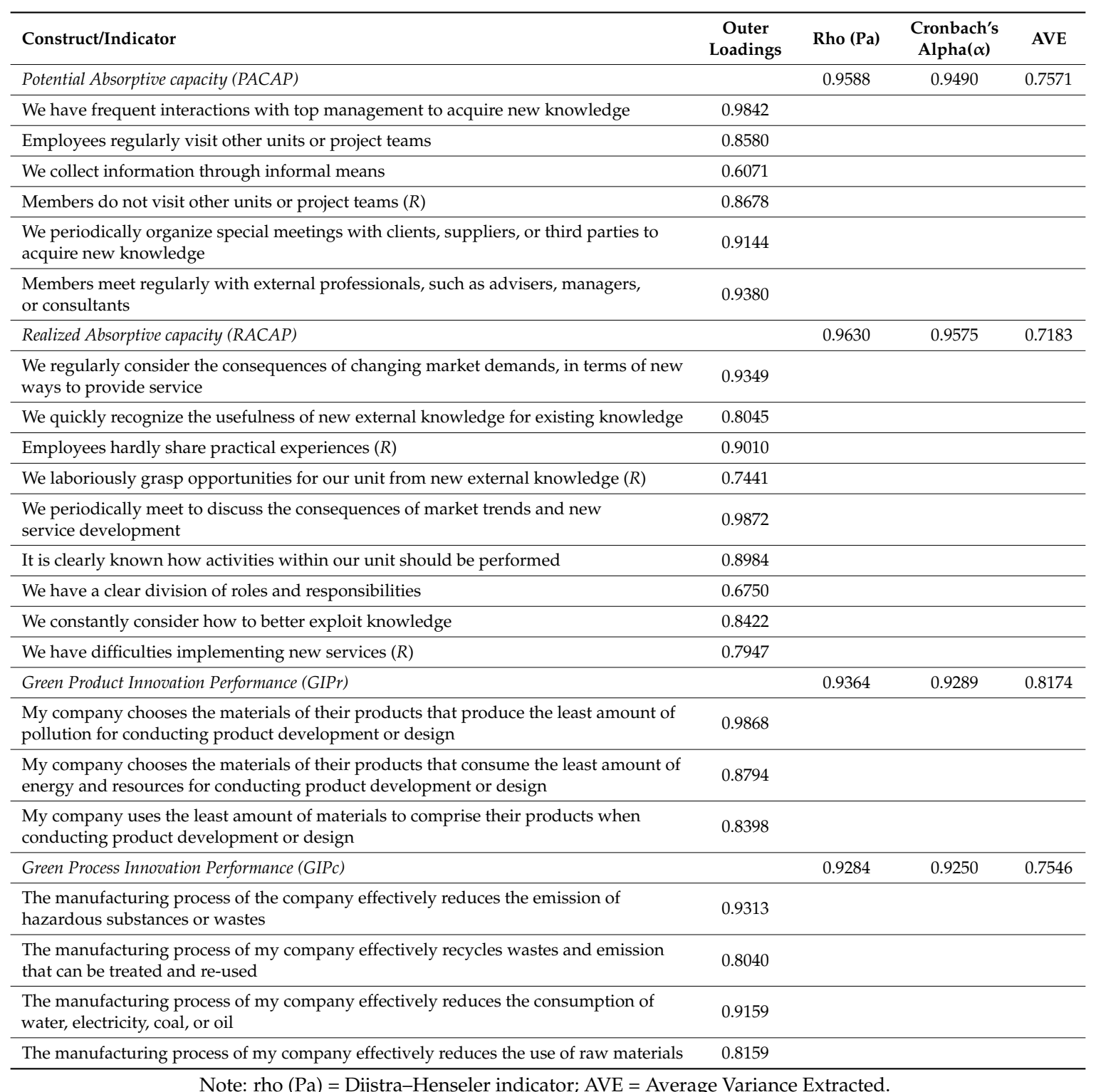


Table 3. Measurement model: discriminant validity.

\begin{tabular}{ccccc}
\hline \multicolumn{5}{c}{ Heterotrait-Monotrait Ratio (HTMT) } \\
\hline GIPr & GIPr & GIPc & PACAP & RACAP \\
GIPc & 1.0028 & & & \\
PACAP & 0.1905 & 0.2125 & & \\
RACAP & 0.4418 & 0.5123 & 0.2691 & \\
\hline
\end{tabular}

\subsection{Structural Model}

The algebraic sign, magnitude and significance of the structural path coefficients and the adjusted coefficient of determination $\left(R^{2}\right)$ values for predictive relevance allow an evaluation of the structural model (Table 4).

Table 4. Structural model results for the mediation model.

\begin{tabular}{|c|c|c|c|c|c|}
\hline $\begin{array}{c}\text { Direct Effects on } \\
\text { Endogenous Constructs }\end{array}$ & Path Coefficient & $t$-Value & $p$-Value & $95 \%$ BCCI & Support \\
\hline $\begin{array}{c}\text { RACAP } \rightarrow \text { GIP Product } \\
\left(R^{2}=0.2389\right)\end{array}$ & $0.4703^{* * *}$ & 5.7430 & 0.0000 & {$[0.3199 ; 0.6392]$} & Yes \\
\hline $\begin{array}{c}\text { RACAP } \rightarrow \text { GIP Process } \\
\left.\left(R^{2}=0.1791\right)\right)\end{array}$ & $0.3972 * * *$ & 4.5240 & 0.0000 & {$[0.2344 ; 0.5720]$} & Yes \\
\hline $\begin{array}{l}\text { PACAP } \rightarrow \text { RACAP } \\
\quad\left(R^{2}=0.0727\right)\end{array}$ & $0.2697^{* *}$ & 2.3727 & 0.0089 & {$[0.0664 ; 0.5005]$} & Yes \\
\hline $\begin{array}{c}\text { Indirect Effects on } \\
\text { Endogenous Constructs }\end{array}$ & Path Coefficient & $t$-Value & $p$-Value & $95 \%$ BCCI & Support \\
\hline $\begin{array}{c}\text { PACAP } \rightarrow \text { GIP Product } \\
\left(R^{2}=0.2389\right)\end{array}$ & 0.1268 * & 2.0550 & 0.0201 & {$[0.0295 ; 0.2675]$} & Yes \\
\hline $\begin{array}{c}\text { PACAP } \rightarrow \text { GIP Process } \\
\left(R^{2}=0.1791\right)\end{array}$ & 0.1071 * & 1.8419 & 0.0329 & {$[0.0231 ; 0.2431]$} & Yes \\
\hline
\end{tabular}

Notes: BCCI: bias corrected confidence intervals; $t(0.05,4999)=1.645 ; t(0.01,4999)=2.327 ; t(0.001,4999)=3.092$. ${ }^{*} p<0.05 .{ }^{* *} p<0.01 .{ }^{* * *} p<0.001$.

Following [67], the operation of the bootstrapping technique used 5000 re-samples, in order to generate the standard errors and $t$-values ( $t$-statistics), which allowed us to check the significance statistics of the relationship hypothesized within the proposed models.

The results offer empirical evidence to sustain all the relationships hypothesized within the research model, both direct or indirect (mediated). Specifically, we applied a percentile approach, which has the advantage of being completely distribution free [68]. A 95\% bootstrap confidence interval for the indirect effects is always greater than zero. Hence, the results summarized in Table 4 confirm that structural model has full mediation [69]. Figure 3 summarizes the structural model results. 


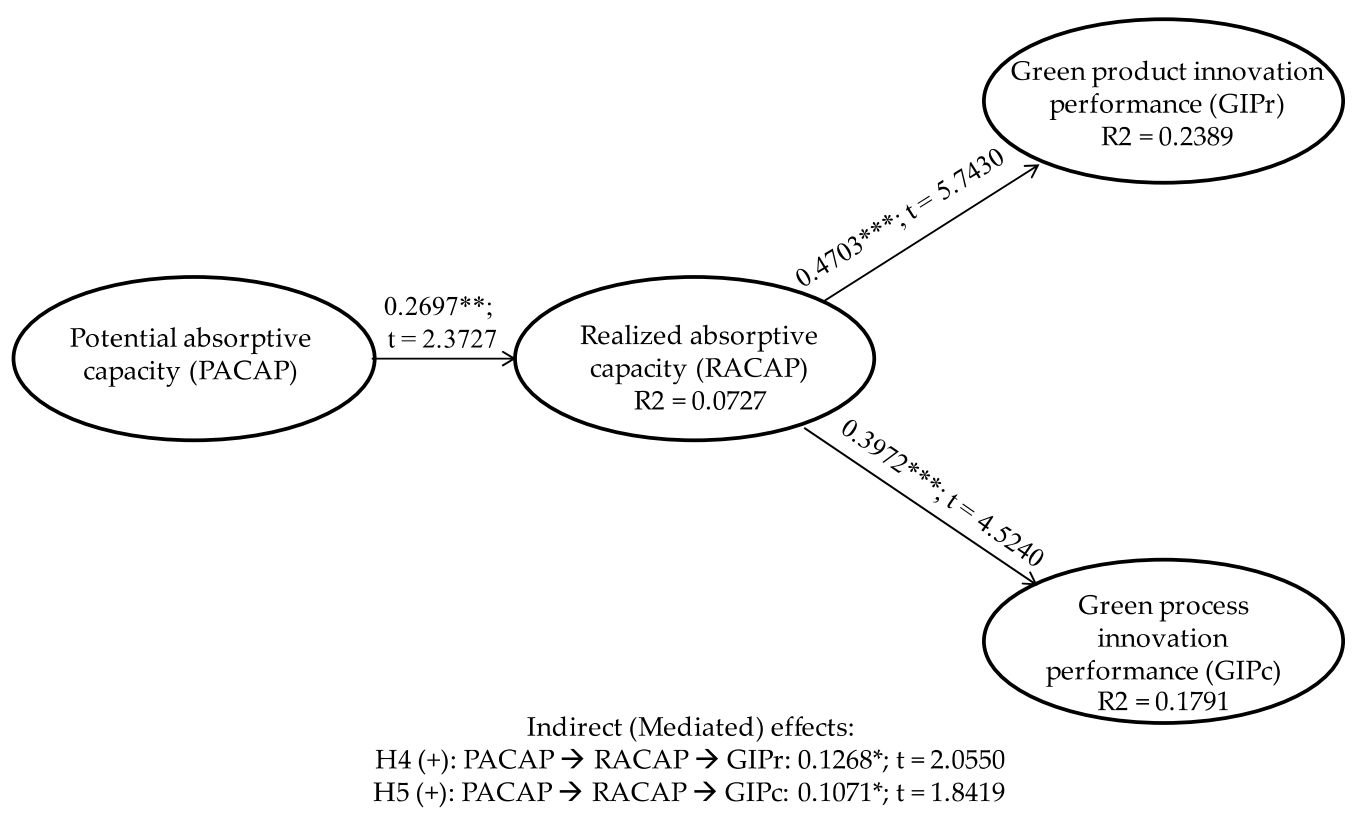

Figure 3. Summary of structural model results.

\subsection{Additional Interaction Analysis}

Additionally, using the PLS characteristic of exploration [70], this paper explores the moderating role exerted by PACAP on the RACAP-GIPr and RACAP-GIPc links. The reason underlying this supplementary analysis roots in the fact that [14,71]'s seminal conceptualizations of absorptive capacity are essentially conceptual models, not path diagrams, and consequently they may admit more than one interpretation in data analysis.

Following [72], since the outcome and/or the moderator variable are modeled as composites, it is not accurate to use the product indicator approach-pairwise multiplication of indicators. Therefore, we relied on the use of the two-stage approach, as suggested by [73]. This method consists of running the PLS path model to obtain construct scores of the outcome and moderator variables (stage 1). Subsequently, the interaction term (i.e., PACAP $\times$ RACAP) is made up as the element-wise product of the construct scores of PACAP and RACAP (stage 2). Table 5 comprises the structural model results for this supplementary structural model under analysis. As may be observed, our results fail to offer empirical evidence to show that PACAP exerts a moderating role in the RACAP-GIP ties.

Table 5. Structural model results for the interaction model.

\begin{tabular}{|c|c|c|c|c|}
\hline $\begin{array}{c}\text { Direct Effects on } \\
\text { Endogenous Constructs }\end{array}$ & Path Coefficient & $t$-Value & $p$-Value & $95 \%$ BCCI \\
\hline $\begin{array}{l}\mathrm{RACAP} \rightarrow \mathrm{GIPr} \\
\left(R^{2}=0.2316\right)\end{array}$ & 0.4934 & 6.8486 & 0.0000 & {$[0.3600 ; 0.6369]$} \\
\hline $\begin{array}{l}\mathrm{RACAP} \rightarrow \mathrm{GIPC} \\
\quad\left(R^{2}=0.1767\right)\end{array}$ & 0.4275 & 5.3323 & 0.0000 & {$[0.2665 ; 0.5853]$} \\
\hline Interaction Effects & Path Coefficient & $t$-Value & $p$-Value & 95\% BCCI \\
\hline $\begin{array}{c}\mathrm{PACAP} \times \mathrm{RACAP} \rightarrow \mathrm{GIPr} \\
\left(R^{2}=0.2316\right)\end{array}$ & 0.0902 & 1.2111 & 0.2261 & {$[-0.0588 ; 0.2380]$} \\
\hline $\begin{array}{c}\mathrm{PACAP} \times \mathrm{RACAP} \rightarrow \mathrm{GIPC} \\
\left(R^{2}=0.1767\right)\end{array}$ & 0.1273 & 1.5506 & 0.1213 & {$[-0.0450 ; 0.2806]$} \\
\hline
\end{tabular}




\section{Discussion}

Currently, firms are in need of information that can be used to facilitate their engagement in innovation activities, such as green innovation. This type of innovation requires new knowledge to be assimilated and transformed within the organization. Thus, absorptive capacity could be seen as playing a key role in inducing a firm's intention to implement green innovation practices [13], because it applies new knowledge for the attainment of products, services or processes that involve significant improvements or novelty with respect to existing ones [74,75]. Plenty of research studies have argued the existence of a direct link between absorptive capacity and green innovation $[5,13]$. However, the links between absorptive capacity and green product and process innovation performance have been scarcely explored. There are no studies that have analyzed the relationships between the two dimensions of absorptive capacity and green product and process innovation. Hence, building upon the previous literature, this paper developed a research model that links these constructs.

The empirical results of this study suggest that potential absorptive capacity is an antecedent or driver of realized absorptive capacity, which is subsequently positively related to both green product innovation performance and green process innovation performance. The positive effects that empirical results show for $\mathrm{H} 2, \mathrm{H} 3, \mathrm{H} 4$ and $\mathrm{H} 5$ reveal that absorptive capacity positively drives green innovation performance, both contributing to launching more sustainable innovative products and to deploying more sustainable innovative processes. Moreover, realized absorptive capacity plays a mediator role between potential absorptive capacity and green process and product innovation performance. It explains that organizations cannot exploit external knowledge without previously having acquired and assimilated it, which suggests that PACAP precedes RACAP [14]. With a higher probability of interpreting new knowledge (PACAP), an organization will be more proactive in the exploitation of new opportunities that arise in the organization's environment (RACAP). Therefore, PACAP can also provide an incentive for increasing RACAP.

Furthermore, the empirical results derived from the PLS analysis of the research model predict stronger effects (both direct and indirect) of absorptive capacity on green product innovation performance (GIPr) than on green process innovation performance (GIPc). This suggests that although the links between absorptive capacity dimensions and GIPc are positive and significant, in our sample, ACAP performed slightly better at predicting GIPc. However, this difference was very minor and hence, we can argue that our research outcomes offer empirical evidence to show the influence of ACAP on both types of GIP.

\subsection{Theoretical Contribution}

The article makes several theoretical contributions. First, we studied the effect of PACAP on RACAP, and the effects of RACAP on GIPr and GIPc. Secondly, we tested how the PACAP dimension affects each of the types of green innovation via RACAP. To this aim, we used survey-based research with a sample of 112 Spanish firms belonging to the automotive equipment and components manufacturers sector. Finally, our mediation model provides practical steps for managers interested in knowing how potential and realized absorptive capacity can generate green innovation performance in their company.

Further, this paper not only tests a research model and hypotheses, but critically assesses whether the PACAP variable exerts an antecedent or a moderating role. In this way, our analysis sheds light on the PACAP-RACAP-GIP linkages, according to two theoretical pathways, one being the interaction effect (moderating role of PACAP) regarding the interpretation of antecedence and complementarity between the two dimensions of absorptive capacity and the other being the theory that models PACAP as an antecedent of RACAP (path diagram) and finds its logical explanation in Zahra and George's seminal work [14]. In our case, the results derived from the PLS analysis uphold the direct effect that RACAP exerts on both types of GIP and the mediating effect exerted by RACAP in the PACAP-GIP links (indirect effect). However, they fail to offer empirical evidence to show that PACAP exerts a moderating role in the RACAP-GIP ties. This outcome contributes to enlarging the understanding of 
the non-linear linkages between the two subsets of absorptive capacity and performance variables [14] and, despite failing to find empirical support for this moderating effect, perhaps this idea might contribute to opening a new and disruptive research avenue within this field.

Finally, the outcomes derived from this paper are in line with the findings comprised at $[75,76]$, although they comprise substantial differences, since the research model posited in this study entails a disaggregation of the main constructs using the first order variables that form both constructs. Therefore, the objective of this paper is to deepen the knowledge of the relationships between the constructs in a disaggregated way. Consequently, the research hypotheses posited follow an open "black box" approach. This outcome contributes to enlarging the understanding of the non-linear linkages between the constructs under study.

\subsection{Managerial Implications}

The managerial and practical implications are strong. Along this paper, our purpose was to focus on the importance of absorptive capacity (ACAP) on green process and product innovation performance (GIPr and GIPc). Our results highlight the importance of transforming and exploiting the knowledge acquired to obtain green innovation performance. Companies may not generate green innovation performance only with the acquisition of knowledge. It should be adapted and transformed to the circumstances of each company and sector. Along this vein, managers should focus on strengthening their firm's realized absorptive capacity, given the critical role (both directly and mediating) it plays, while fostering GIP. Therefore, managers should uphold and endorse their employees in developing practices such as recording and storing newly acquired knowledge for future reference, recognizing the usefulness of new external knowledge for existing knowledge, sharing practical experiences, grasping opportunities for their unit, periodically meeting to discuss the consequences of market trends, thoroughly evaluating customers' complaints and constantly assessing how to better exploit organizational knowledge, among others.

To attain competitive advantages, firms belonging to the Spanish automotive component manufacturing sector should let their employees regularly maintain contact with other units, divisions or teams as well as with outside professionals, such as consultants or advisors. Therefore, firms might improve their ability to acquire and assimilate the external knowledge compulsory for meeting their main customers' (i.e., large automakers) requirements. When employees work in isolation and fail to visit other units, divisions or teams, or they are simply slow in recognizing the trends in their environment, the firm's absorptive capacity might be negatively affected.

Overall, managers of ACMS firms must attempt to absorb new external knowledge, which may contribute to reducing the environmental impact caused by its industrial and commercial activities, without sacrificing the levels of quality, costs, reliability, performance, or the efficient use of energy. At the same time, these firms must meet ecological regulations, diminishing their ecological footprint, and leading to overall economic benefit [77]. In this way, automakers will continue to work with them in the design and development of new green vehicles.

\subsection{Limitations and Future Research}

The present study recognizes a series of limitations in its results and conclusions. First, we were able to provide just a snapshot of ongoing processes. Consequently, we were unable to investigate the intricacies of the processes and capabilities over time. Second, another limitation comes from the technique used for the proposed model-structural equations-which assumes linearity in relationships between latent variables. Third, the model of this study does not capture possible moderating effects of environmental turbulence or the effect of control variables. Fourth, there are limitations to using sectorial characteristics-while having the advantage of allowing the network to be analyzed at a global level, they show little cohesion. Finally, obtaining green product and process innovation performance depends on the characteristics of the empirical context that is analyzed. For future research, we plan to examine the moderating effect of environmental variables that we expect 
might influence the results. Also, it might be then interesting to change this particular geographical context (Spain) or this specific sector (ACMS) in further studies, in an attempt to generalize our insights and conclusions.

Acknowledgments: The authors are very grateful to the participants of the IFKAD Conference (7-9 June 2017, Saint Petersburg) for their comments and suggestions that significantly contributed to enhance the final version of this study. The authors also express their gratitude to Reviewer 1 for his/her invaluable help in understanding the intricacies of the non-linear relationships between the variables shaping our research model.

Author Contributions: All authors were involved in the documentation phase, in choosing the research methodology, in data analysis, as well as in results analysis and discussion. All authors participated in the manuscript preparation and have approved the submitted manuscript.

Conflicts of Interest: The authors declare no conflict of interest.

\section{Appendix A}

1. Absorptive Capacity

Potential absorptive capacity (PACAP) $(1=$ completely disagree and $7=$ completely agree $)$

In my organization:

- We have frequent interactions with top management to acquire new knowledge.

- Employees regularly visit other units or project teams.

- We collect information through informal means (e.g., lunches with colleagues, friends, and chats with partners).

- Members do not visit other units or project teams (reverse).

- We periodically organize special meetings with clients, suppliers, or third parties to acquire new knowledge.

- Members meet regularly with external professionals, such as advisers, managers, or consultants.

- We are slow to recognize shifts in our market (competitors, laws, demographic changes, etc.) (reverse).

- New opportunities to serve our clients are quickly understood.

- We quickly analyze and interpret changing client demands.

Realized absorptive capacity (RACAP) $(1=$ completely disagree and $7=$ completely agree $)$

In my organization:

- We regularly consider the consequences of changing market demands, in terms of new ways to provide services.

- Employees record and store newly acquired knowledge for future reference.

- We quickly recognize the usefulness of new external knowledge for existing knowledge.

- Employees hardly share practical experiences (reverse).

- We laboriously grasp opportunities for our unit from new external knowledge (reverse).

- We periodically meet to discuss the consequences of market trends and new service development.

- It is clearly known how activities within our unit should be performed.

- Clients' complaints fall on deaf ears in our unit (reverse).

- We have a clear division of roles and responsibilities.

- We constantly consider how to better exploit knowledge.

- We have difficulty implementing new services (reverse).

- Employees have a common language regarding our services. 
2. Green product innovation performance (GIPr) $(1=$ high disagreement and $7=$ high agreement $)$

- My company chooses the materials of the product that produce the least amount of pollution for conducting product development or design.

- My company chooses the materials of their products that consume the least amount of energy and resources for conducting product development or design.

- My company uses the least amount of materials to comprise their products for conducting the product development or design.

- My company circumspectly evaluates whether their products are easy to recycle, reuse, and decompose when conducting the product development or design.

3. Green process innovation performance (GIPc) $(1=$ high disagreement and $7=$ high agreement $)$

- The manufacturing process of the company effectively reduces the emission of hazardous substances or wastes.

- The manufacturing process of my company effectively recycles wastes and emission that can be treated and re-used.

- The manufacturing process of my company effectively reduces the consumption of water, electricity, coal, or oil.

- The manufacturing process of my company effectively reduces the use of raw materials.

\section{References}

1. Leal-Millán, A.; Peris-Ortiz, M.; Leal-Rodríguez, A.L. The Route Towards Sustainable Innovation and Entrepreneurship: An Overview. In Sustainability in Innovation and Entrepreneurship; Springer: Cham, Switzerland, 2017; pp. 1-9.

2. Albort-Morant, G.; Leal-Millán, A.; Cepeda-Carrión, G. The antecedents of green innovation performance: A model of learning and capabilities. J. Bus. Res. 2016, 69, 4912-4917. [CrossRef]

3. Albort-Morant, G.; Henseler, J.; Leal-Millán, A.; Cepeda-Carrión, G. Mapping the Field: A Bibliometric Analysis of Green Innovation. Sustainability 2017, 9, 1011. [CrossRef]

4. Leal-Rodríguez, A.L.; Ariza-Montes, A.J.; Morales-Fernández, E.; Albort-Morant, G. Green innovation, indeed a cornerstone in linking market requests and business performance. Evidence from the Spanish automotive components industry. Technol. Forecast. Soc. Chang. 2017. [CrossRef]

5. Chen, Y.S.; Chang, C.H.; Lin, Y.H. The Determinants of green radical and incremental innovation performance: Green shared vision, green absorptive capacity, and green organizational ambidexterity. Sustainability 2014, 6, 7787-7806. [CrossRef]

6. Buhl, A.; Blazejewski, S.; Dittmer, F. The More, the Merrier: Why and How Employee-Driven Eco-Innovation Enhances Environmental and Competitive Advantage. Sustainability 2016, 8, 946. [CrossRef]

7. Lai, S.B.; Wen, C.T.; Chen, Y.S. The exploration of the relationship between the environmental pressure and the corporate competitive advantage. In Proceedings of the 2003 CSMOT Academic Conference, National Chiao Tung University, Hsin-Chu, Taiwan, 22 September 2003.

8. Chen, Y.S.; Lai, S.B.; Wen, C.T. The influence of green innovation performance on corporate advantage in Taiwan. J. Bus. Ethics 2006, 67, 331-339. [CrossRef]

9. Fosfuri, A.; Tribó, J.A. Exploring the antecedents of potential absorptive capacity and its impact on innovation performance. Omega 2008, 36, 173-187. [CrossRef]

10. Tsai, W. Knowledge transfer in intraorganizational networks: Effects of network position and absorptive capacity on business unit innovation and performance. Acad. Manag. J. 2001, 44, 996-1004. [CrossRef]

11. Delmas, M.; Hoffmann, V.H.; Kuss, M. Under the tip of the iceberg: Absorptive capacity, environmental strategy, and competitive advantage. Bus. Soc. 2011, 50, 116-154. [CrossRef]

12. Cohen, W.M.; Levinthal, D.A. Absorptive capacity: A new perspective on learning and innovation. Adm. Sci. Q. 1990, 35, 128-152. [CrossRef]

13. Hashim, R.; Bock, A.J.; Cooper, S. The Relationship between Absorptive Capacity and Green Innovation. World Academy of Science, Engineering and Technology. Int. J. Ind. Manuf. Eng. 2015, 9, 1065-1072. 
14. Zahra, S.A.; George, G. Absorptive capacity: A review, reconceptualization, and extension. Acad. Manag. Rev. 2002, 27, 185-203.

15. Lane, P.J.; Koka, B.R.; Pathak, S. The reification of absorptive capacity: A critical review and rejuvenation of the construct. Acad. Manag. Rev. 2006, 31, 833-863. [CrossRef]

16. Setia, P.; Patel, P.C. How information systems help create OM capabilities: Consequents and antecedents of operational absorptive capacity. J. Oper. Manag. 2013, 31, 409-431. [CrossRef]

17. Auguste, M.S.C.; Jashapara, A.; Bernroider, E. Exploring the Perceived Influence of New Knowledge on Absorptive Capacity in a Public Sector Organisation; José-Rodrigo Córdoba School of Management, Royal Holloway University of London: London, UK, 2010; p. 6.

18. Noblet, J.P.; Simon, E.; Parent, R. Absorptive capacity: A proposed operationalization. Knowl. Manag. Res. Pract. 2011, 9, 367-377. [CrossRef]

19. Mariano, S.; Walter, C. The construct of absorptive capacity in knowledge management and intellectual capital research: Content and text analyses. J. Knowl. Manag. 2015, 19, 372-400. [CrossRef]

20. Bhupendra, K.V.; Sangle, S. What drives successful implementation of pollution prevention and cleaner technology strategy? The role of innovative capability. J. Environ. Manag. 2015, 155, 184-192. [CrossRef] [PubMed]

21. Gabler, C.B.; Richey, R.G., Jr.; Rapp, A. Developing an eco-capability through environmental orientation and organizational innovativeness. Ind. Mark. Manag. 2015, 45, 151-161. [CrossRef]

22. Castiaux, A. Developing dynamic capabilities to meet sustainable development challenges. Int. J. Innov. Manag. 2012, 16, 1240013. [CrossRef]

23. Henseler, J.; Ringle, C.M.; Sinkovics, R.R. The use of partial least squares path modeling in international marketing. In New Challenges to International Marketing; Emerald Group Publishing Limited: Bingley, UK, 2009; pp. 277-319.

24. Kim, L. The dynamics of Samsung's technological learning in semiconductors. Calif. Manag. Rev. 1997, 39, 86-100. [CrossRef]

25. Kim, L. Imitation to Innovation: The Dynamics of Korea's Technological Learning; Harvard Business Press: Boston, MA, USA, 1997.

26. Schiederig, T.; Tietze, F.; Herstatt, C. Green innovation in technology and innovation management-An exploratory literature review. $R$ D Manag. 2012, 42, 180-192. [CrossRef]

27. Fussler, C.; James, P. A Breakthrough Discipline for Innovation and Sustainability; Pitman Publishing: London, UK, 1996.

28. Halila, F.; Rundquist, J. The development and market success of eco-innovations: A comparative study of eco-innovations and "other" innovations in Sweden. Eur. J. Innov. Manag. 2011, 14, 278-302. [CrossRef]

29. Damanpour, F. Organizational innovation: A meta-analysis of effects of determinants and moderators. Acad. Manag. J. 1991, 34, 555-590. [CrossRef]

30. Porter, M.E. The competitive advantage of nations. Harv. Bus. Rev. 1990, 68, 73-93.

31. OECD, E. Oslo Manual: Guidelines for Collecting and Interpreting Innovation Data; OECD: Paris, France, 2005.

32. Kemp, R.; Pearson, P. Final Report MEI Project about Measuring Eco-Innovation; Community Research and Development Information Service: Maastricht, The Netherlands, 2008.

33. Hart, S.L. A natural-resource-based view of the firm. Acad. Manag. Rev. 1995, 20, 986-1014.

34. Porter, M.E.; Van der Linde, C. Toward a new conception of the environment-competitiveness relationship. J. Eco. Perspect. 1995, 9, 97-118. [CrossRef]

35. Chang, C.H. The influence of corporate environmental ethics on competitive advantage: The mediation role of green innovation. J. Bus. Ethics 2011, 104, 361-370. [CrossRef]

36. Leal-Millán, A.; Roldán, J.L.; Leal-Rodríguez, A.L.; Ortega-Gutiérrez, J. IT and relationship learning in networks as drivers of green innovation and customer capital: Evidence from the automobile sector. J. Knowl. Manag. 2016, 20, 444-464. [CrossRef]

37. Klassen, R.D.; Whybark, D.C. The impact of environmental technologies on manufacturing performance. Acad. Manag. J. 1999, 42, 599-615. [CrossRef]

38. Tseng, M.L.; Huang, F.H.; Chiu, A.S. Performance drivers of green innovation under incomplete information. Procedia Soc. Behav. Sci. 2012, 40, 234-250. [CrossRef]

39. Chen, Y.S. The driver of green innovation and green image-green core competence. J. Bus. Ethics 2008, 81, 531-543. [CrossRef] 
40. Fiol, C.M. Squeezing harder doesn't always work: Continuing the search for consistency in innovation research. Acad. Manag. Rev. 1996, 21, 1012-1021. [CrossRef]

41. Lane, P.J.; Lubatkin, M. Relative absorptive capacity and interorganizational learning. Strateg. Manag. J. 1998, 19, 461-477. [CrossRef]

42. Cepeda-Carrión, G.; Gabriel Cegarra-Navarro, J.; Leal-Millán, A.G. Finding the hospital-in-the-home units' innovativeness. Manag. Decis. 2012, 50, 1596-1617. [CrossRef]

43. Barney, J. Firm resources and sustained competitive advantage. J. Manag. 1991, 17, 99-120. [CrossRef]

44. Beckenbach, F.; Daskalakis, M. Invention and Innovation as Creative Problem-Solving Activities; Springer: New York, NY, USA, 2013; pp. 1118-1131.

45. Nonaka, I.; Takeuchi, H. The Knowledge-Creating Company: How Japanese Companies Create the Dynamics of Innovation; Oxford University Press: Oxford, UK, 1995.

46. Van Den Bosch, F.A.; Van Wijk, R.; Volberda, H.W. Absorptive capacity: Antecedents, models and outcomes. In Handbook of Organizational Learning and Knowledge Management; Blackwell: Hoboken, NJ, USA, 2003.

47. Lichtenthaler, U. Absorptive capacity, environmental turbulence, and the complementarity of organizational learning processes. Acad. Manag. J. 2009, 52, 822-846. [CrossRef]

48. Leal-Rodríguez, A.L.; Roldán, J.L.; Ariza-Montes, J.A.; Leal-Millán, A. From potential absorptive capacity to innovation outcomes in project teams: The conditional mediating role of the realized absorptive capacity in a relational learning context. Int. J. Proj. Manag. 2014, 32, 894-907. [CrossRef]

49. Gluch, P.; Gustafsson, M.; Thuvander, L. An absorptive capacity model for green innovation and performance in the construction industry. Constr. Manag. Econ. 2009, 27, 451-464. [CrossRef]

50. Chen, Y.S.; Lin, Y.H.; Lin, C.Y.; Chang, C.W. Enhancing green absorptive capacity, green dynamic capacities and green service innovation to improve firm performance: An analysis of structural equation modeling (SEM). Sustainability 2015, 7, 15674-15692. [CrossRef]

51. Leal-Rodríguez, A.L.; Roldán, J.L.; Leal, A.G.; Ortega-Gutiérrez, J. Knowledge management, relational learning, and the effectiveness of innovation outcomes. Serv. Ind. J. 2013, 33, 1294-1311. [CrossRef]

52. Leal-Rodríguez, A.L.; Ariza-Montes, J.A.; Roldán, J.L.; Leal-Millán, A.G. Absorptive capacity, innovation and cultural barriers: A conditional mediation model. J. Bus. Res. 2014, 67, 763-768. [CrossRef]

53. Limaj, E.; Bernroider, E.W. The roles of absorptive capacity and cultural balance for exploratory and exploitative innovation in SMEs. J. Bus. Res. 2017, in press. [CrossRef]

54. Bower, J.L.; Christensen, C.M. Disruptive technologies: Catching the wave. Harv. Bus. Rev. 1995, 73, 43-53.

55. Ali, M.; Ali, I.; Al-Maimani, K.A.; Park, K. The effect of organizational structure on absorptive capacity in single and dual learning modes. J. Innov. Knowl. 2017, in press. [CrossRef]

56. Lee, C.Y.; Wu, F.C. Factors affecting knowledge transfer and absorptive capacity in multinational corporations. J. Int. Manag. Stud. 2010, 5, 118-126.

57. Yu, Y.; Dong, X.Y.; Shen, K.N.; Khalifa, M.; Hao, J.X. Strategies, Technologies, and Organizational Learning for Developing Organizational Innovativeness in Emerging Economies. J. Bus. Res. 2013, 66, 2507-2514. [CrossRef]

58. Sernauto. Annual Memory 2016. 2016. Available online: http://www.sernauto.es/images/memorias_ sernauto/2016/ (accessed on 18 April 2016).

59. Gerrard, J.; Kandlikar, M. Is European end-of-life vehicle legislation living up to expectations? Assessing the impact of the ELV Directive on 'green'innovation and vehicle recovery. J. Clean. Prod. 2007, 15, 17-27. [CrossRef]

60. Jansen, J.J.; Van Den Bosch, F.A.; Volberda, H.W. Managing potential and realized absorptive capacity: How do organizational antecedents matter? Acad. Manag. J. 2005, 48, 999-1015. [CrossRef]

61. Rigdon, E.E. Choosing PLS path modeling as analytical method in European management research: A realist perspective. Eur. Manag. J. 2016, 34, 598-605. [CrossRef]

62. Henseler, J.; Dijkstra, T.K. ADANCO 2.0. Composite Modeling, Kleve. 2015. Available online: www.compositemodeling.com (accessed on 14 December 2015).

63. Henseler, J.; Hubona, G.; Ray, P.A. Using PLS path modeling in new technology research: Updated guidelines. Ind. Manag. Data Syst. 2016, 116, 2-20. [CrossRef]

64. Henseler, J. Adanco 2.0.1. User Manual; Composite Modeling GmbH \& Co.: KG, Kleve, Germany, 2017.

65. Hu, L.T.; Bentler, P.M. Fit indices in covariance structure modeling: Sensitivity to underparameterized model misspecification. Psychol. Methods 1998, 3, 424-453. [CrossRef] 
66. Henseler, J.; Ringle, C.M.; Sarstedt, M. A new criterion for assessing discriminant validity in variance-based structural equation modeling. J. Acad. Mark. Sci. 2015, 43, 115-135. [CrossRef]

67. Hair, J., Jr.; Sarstedt, M.; Hopkins, L.; Kuppelwieser, V. Partial least squares structural equation modeling (PLS-SEM) An emerging tool in business research. Eur. Bus. Rev. 2014, 26, 106-121. [CrossRef]

68. Chin, W.W. How to write up and report PLS analyses. In Handbook of Partial Least Squares; Springer: Berlin/Heidelberg, Germany, 2010; pp. 655-690.

69. Nitzl, C.; Roldán, J.L.; Cepeda-Carrión, G. Mediation Analysis in Partial Least Squares Path Modeling: Helping Researchers Discuss More Sophisticated Models. Ind. Manag. Data Syst. 2016, 116, 1849-1864. [CrossRef]

70. Henseler, J. Partial least squares path modeling: Quo vadis? Qual. Quant. 2018. [CrossRef]

71. Todorova, G.; Durisin, B. Absorptive capacity: Valuing a reconceptualization. Acad. Manag. Rev. 2007, 32, 774-786. [CrossRef]

72. Fassott, G.; Henseler, J.; Coelho, P.S. Testing moderating effects in PLS path models with composite variables. Ind. Manag. Data Syst. 2016, 116, 1887-1900. [CrossRef]

73. Henseler, J.; Fassott, G. Testing Moderating Effects in PLS Path Models: An Illustration of Available Procedures. In Handbook of Partial Least Squares; Springer: Berlin/Heidelberg, Germany, 2010; pp. 713-735.

74. Leal-Rodríguez, A.L.; Albort-Morant, G. Capacidad de absorción del conocimiento y resultados de la innovación: Un estudio empírico en empresas españolas del sector de la automoción. Universitas: Gestão e TI. 2015, 5. [CrossRef]

75. Martelo-Landroguez, S.; Albort-Morant, G.; Leal-Rodríguez, A.L.; Ribeiro-Soriano, B. The Effect of Absorptive Capacity on Green Customer Capital under an Organizational Unlearning Context. Sustainability 2018, 10, 265. [CrossRef]

76. Albort-Morant, G.; Leal-Rodríguez, A.L.; De Marchi, V. Absorptive Capacity and Relationship Learning Mechanisms as Complementary Drivers of Green Innovation Performance. J. Knowl. Manag. 2018, 22, 432-452.

77. Srivastava, S.K. Green supply-chain management: A state-of-the-art literature review. Int. J. Manag. Rev. 2007, 9, 53-80. [CrossRef] 